\title{
Effect of Aluminum-Boron Powders Mechanical Mixtures on the Combustion of High-Energy Materials at Subatmospheric Pressures
}

\author{
Vladimir Arkhipov, Lilia Savel'eva, Nikolay Zolotorev \\ Tomsk State University, Research Institute of Applied Mathematics and Mechanics, Tomsk, Russia
}

\begin{abstract}
This paper presents the results of an experimental study of the high-energy materials combustion at subatmospheric pressures. Systems containing powders of micron-sized aluminum, ultrafine aluminum, boron and their mechanical mixtures were investigated. Effect of the replacement of aluminum by aluminum-boron mixtures in propellant systems on the burning rate law was determined.
\end{abstract}

Keywords: aluminum, boron, powder dispersity, subatmospheric pressure, burning rate law.

\section{Introduction}

One of main component of high-energy materials (HEMs) is a metal fuel. The traditional metal fuel is aluminum, whose influence on the HEMs burning rate was studied in a wide range of pressures in various active media for powders of different dispersion [1-3].

This work presents the results of thermodynamic calculation, the characteristics of the products of combustion of high-energy materials containing a mixture of aluminum-boron, and the results of measurements of the burning rate of compositions in subatmospheric pressure. In the experiment ranged various binder dispersity of aluminum powder and composition of the metal fuel.

We studied HEMs compositions based on ammonium perchlorate (AP) and organic fuel (SKDM-80), containing 15 wt \% metal powders (micron-size aluminum ASD-4, ultrafine aluminum Alex, boron and their mechanical mixtures). Table 1 shows the density $\rho$, dispersity, enthalpy of formation $\Delta H$ and the equivalent formulas HEMs components [4].

Table 1. Characteristics of the HEMs components

\begin{tabular}{|c|c|c|c|c|}
\hline Substance & Diameter, $\mu \mathrm{m}$ & Density, $\mathrm{kg} / \mathrm{m}^{3}$ & $\Delta H, \mathrm{~kJ} / \mathrm{kg}$ & Equivalent formula \\
\hline SKDM-80 & - & $910-940$ & -1086 & $\mathrm{C}_{72.044} \mathrm{H}_{129.169} \mathrm{~S}_{0.142}$ \\
\hline AP & $<50$ & 1950 & -2469 & $\mathrm{H}_{34.043} \mathrm{Cl}_{8.511} \mathrm{O}_{34.043} \mathrm{~N}_{8.511}$ \\
\hline ASD-4 & $10-15$ & 2640 & 0 & $\mathrm{Al}_{37.037}$ \\
\hline Alex & $<0.01$ & 1450 & +1350 & $\mathrm{Al}_{37.037}$ \\
\hline B & amorphous & 2330 & 0 & $\mathrm{~B}_{92.421}$ \\
\hline
\end{tabular}

Characteristics of studied HEMs compositions are presented in the table 2. The oxidizer excess coefficient for these compositions was $\alpha=0.5$.

Table 2. Characteristics of HEMs

\begin{tabular}{|c|c|c|c|c|c|c|}
\hline \multirow{2}{*}{$№$} & \multicolumn{5}{|c|}{ Content of components, \% } & \multirow{2}{*}{$\rho, \mathrm{kg} / \mathrm{m}^{3}$} \\
\cline { 2 - 6 } & SKDM-80 & AP & ASD-4 & Alex & B & 1730 \\
\hline 1 & 15.8 & 69.2 & 15 & 0 & 0 & 1720 \\
\hline 2 & 14.2 & 70.8 & 10 & 0 & 5 & 1670 \\
\hline 3 & 15.8 & 69.2 & 0 & 15 & 0 & 1670 \\
\hline 4 & 14.2 & 70.8 & 0 & 10 & 5 & \\
\hline
\end{tabular}

* numbering compositions preserved for all tabular data

\section{Thermodynamic calculations}

Determine the effect of mixed metal fuel on the thermodynamics characteristics of the fuel composition on inert fuel-binder SKDM-80 performed by calculation according to the program "Astra-4" [5]. For calculating 
thermodynamic characteristics, we need the equivalents formulas and the enthalpy of formation compositions HEM, which are presented in table 3. In table 4 shows the calculated values of adiabatic temperature $T_{\text {ad }}$., specific impulse $I_{\mathrm{sp}}$, the content of $\mathrm{HCl}, \mathrm{Al}_{2} \mathrm{O}_{3}, \mathrm{~B}_{2} \mathrm{O}_{3}$ in the products of combustion at the nozzle exit for fuel systems with a oxidizer excess coefficient $\alpha=0.5$, containing from 10 to $15 \mathrm{wt} \%$ aluminum. The specific impulse $I_{\mathrm{sp}}$ was calculated for the standard value of the expansion ratio $P / P_{a}=40 / 1$ where $P-$ is the combustion chamber pressure, $P_{a}-$ is the pressure of the combustion products at the nozzle exit.

Table 3. Equivalent formulas of HEMs

\begin{tabular}{|c|c|c|}
\hline № & Equivalent formula & $\Delta H, \mathrm{~kJ} k \mathrm{~kg}$ \\
\hline 1 & $\mathrm{C}_{11.383} \mathrm{H}_{42.545} \mathrm{~S}_{0.022} \mathrm{O}_{23.558} \mathrm{Cl}_{15.890} \mathrm{Al}_{5.556} \mathrm{~N}_{5.890}$ & -1911.55 \\
\hline 2 & $\mathrm{C}_{10.230} \mathrm{H}_{41.166} \mathrm{~S}_{0.020} \mathrm{O}_{24.102} \mathrm{Cl}_{6.026} \mathrm{Al}_{3.704} \mathrm{~B}_{4.621} \mathrm{~N}_{6.026}$ & -1934.43 \\
\hline 3 & $\mathrm{C}_{11.383} \mathrm{H}_{42.545} \mathrm{~S}_{0.022} \mathrm{O}_{23.558} \mathrm{Cl}_{15.890} \mathrm{Al}_{5.556} \mathrm{~N}_{5.890}$ & -1709.08 \\
\hline 4 & $\mathrm{C}_{10.230} \mathrm{H}_{41.166} \mathrm{~S}_{0.020} \mathrm{O}_{24.102} \mathrm{Cl}_{6.026} \mathrm{Al}_{3.704} \mathrm{~B}_{4.621} \mathrm{~N}_{6.026}$ & -1799.43 \\
\hline
\end{tabular}

The program "Astra-4" does not allow to estimate the influence of dispersion of the starting components for thermodynamic characteristics, therefore, the compositions of 1,3 and 2,4 will be described by a single value.

Table 4. Thermodynamic characteristics of HEMs

\begin{tabular}{|c|c|c|c|c|c|c|c|}
\hline $\begin{array}{c}\text { Composition } \\
\text { number }\end{array}$ & metal fuel & $T_{\text {ad. }}, \mathrm{K}$. & $\begin{array}{c}\mathrm{I}_{\text {sp. }} \\
\text { sec. }\end{array}$ & $\begin{array}{c}\text { cond. phase, } \\
\text { mole/kg }\end{array}$ & $\mathrm{Z}, \%$ & $\begin{array}{c}\mathrm{HCl}, \\
\mathrm{mole} / \mathrm{kg}\end{array}$ & $\mathrm{HCl}, \%$ \\
\hline 1,3 & $\mathrm{Al}$ & 3074 & 264 & $2.8 \mathrm{Al}_{2} \mathrm{O}_{3}$ & 28.3 & 6.5 & 25.1 \\
\hline 2,4 & $\mathrm{Al} / \mathrm{B}$ & 2919 & 267 & $\begin{array}{c}1.8 \mathrm{Al}_{2} \mathrm{O}_{3}, \\
1.0 \mathrm{~B}_{2} \mathrm{O}_{3}\end{array}$ & 25.4 & 6.0 & 23.2 \\
\hline
\end{tabular}

The introduction of boron into the metal fuel, ceteris paribus, lead to a slight increase of specific impulse HEM while reducing the content of condensed substances and hydrogen chloride in the combustion products.

\section{Experimental technique}

Investigated model HEMs compositions comprising ammonium perchlorate, inert combustible binder on the basis of rubber SKDM-80 and mixed metal fuel, constituting a mixture of powders of aluminum and boron of not more than $15 \mathrm{wt} \%$.

The samples were formed by the method mechanical mixing of loose components HEM of fuel-binder. Fuel mass was pressed in a form. The prepared samples were of cylindrical shape with a diameter of $10 \mathrm{~mm}$ and a height of $30 \mathrm{~mm}$. The samples were cured at room temperature for $24 \mathrm{~h}$, and the samples were sorted out based on mechanical integrity criteria and on density values. In the study we used samples with a spread in density not exceeding $0.02 \mathrm{~g} / \mathrm{cm}^{3}$.

Model fuel compositions differed dispersion of aluminum and composition of metal fuel, other components and their ratio were the same. To investigate the influence of dispersion of aluminum powder on the characteristics of the considered HEMs compositions used the micron-size powder ASD -4 and ultrafine powder Alex.

Scheme of the experimental apparatus for studying the combustion process in the pressure range 0.01-0.10 $\mathrm{MPa}$ is shown in Fig. 1. The study was performed under the vacuum shell, the ignition of the sample was ignited by an electric blasting cap.

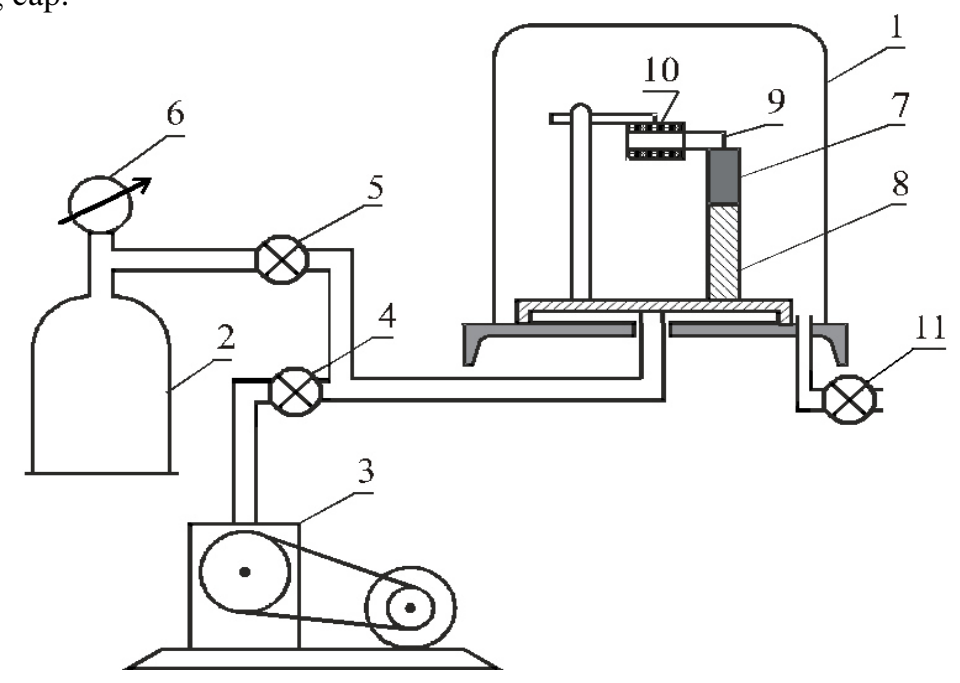

Figure 1. Diagram of experimental setup:

1 - vacuum bell jar; 2 - receiver; 3 - vacuum pump with an electric motor; 4,5,11 - valves;6 - manometer; 7 sample; 8 - stand; 9 - electric blasting cap; 10 - electromagnet 
In order to analyze burning rate HEMs used a power law:

$$
u=u_{1}\left(\frac{d}{d_{\dot{r} t m}}\right)^{v},
$$

where $u$ - burning rate; $u_{1}$ - burning rate at atmospheric pressure; $d_{\dot{r} t m}$ - atmospheric pressure; $d$ - pressure in burning chamber; $v-$ is the exponent in the power-law burning rate

\section{Analysis of results}

In table 5 shows experimental data on the burning rate HEMs in the pressure range $0.03-0.1 \mathrm{MPa}$, averaged over three duplicate experiments.

Table 5. Experimental data on the burning rate

\begin{tabular}{|c|c|c|c|c|}
\hline \multirow{2}{*}{ Pressure, MPa } & \multicolumn{4}{|c|}{ The burning rate of compositions, $\mathrm{mm} / \mathrm{s}$} \\
\cline { 2 - 5 } & 1 & 2 & 3 & 4 \\
\hline 0.1 & $1.14 \pm 0.02$ & $1.43 \pm 0.01$ & $2.13 \pm 0.04$ & $2.22 \pm 0.04$ \\
\hline 0.05 & $0.72 \pm 0.02$ & $1.28 \pm 0.03$ & $1.65 \pm 0.03$ & $1.81 \pm 0.03$ \\
\hline 0.04 & $0.56 \pm 0.01$ & - & $1.26 \pm 0.01$ & - \\
\hline 0.03 & $0.37 \pm 0.01$ & $0.97 \pm 0.03$ & $0.96 \pm 0.01$ & $1.06 \pm 0.02$ \\
\hline$v$ & 0.88 & 0.78 & 0.6 & 0.54 \\
\hline
\end{tabular}

It should be noted that at pressures below $0.03 \mathrm{MPa}$ stable combustion of the samples was observed. These compositions HEMs is not able to maintain an independent burning at subatmospheric pressures.

Along with the change in burning rate varies and the exponent in the power-law burning rate. The burning rate HEM containing metal aluminum fuel ASD-4 is more dependent on pressure than similar compositions containing Alex.

In Fig. 2 gives curves of the efficiency $K(p)$ for the complete replacement of aluminum ASD-4 on Alex $\left(K_{1}\right)$, the use of mixed metal fuel ASD-4/B $\left(K_{2}\right)$, and Alex/B $\left(K_{3}\right)$.

The efficiency of the use of metal fuels was estimated by the formula:

$$
K=\frac{u_{\text {modif }}}{u_{R S D}},
$$

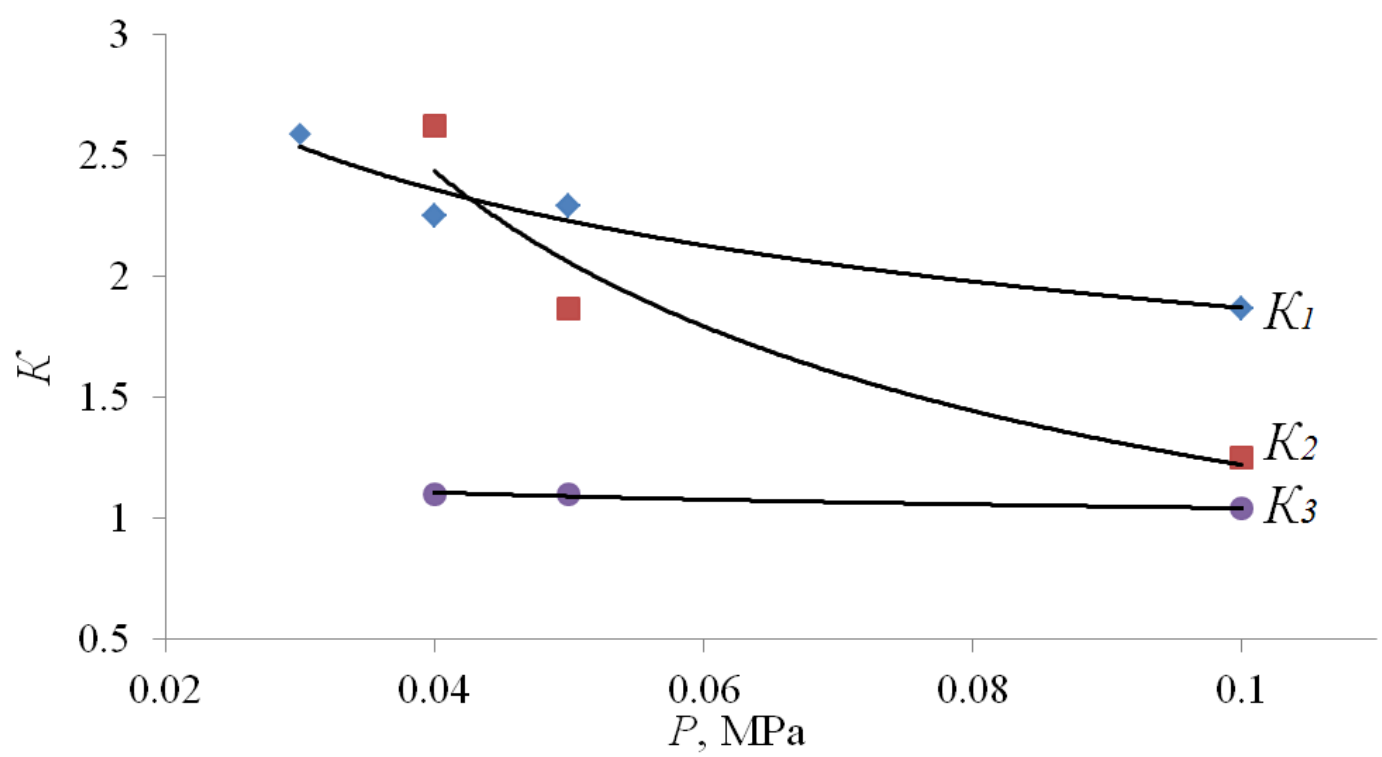

Figure 2. The dependence efficiency of pressure.

It should be noted that regardless of the composition of the modified metal fuel, efficiency of its influence on the burning rate of the studied compounds increases with decreasing subatmospheric pressure.

The greatest influence on the burning rate HEMs has a complete replacement of ASD-4 on Alex $\left(K_{1}\right)$

The introduction of boron in the composition of the mixed metal fuel has a significant impact on the burning rate HEM using the ASD-4 $\left(K_{2}\right)$.

The burning rate HEMs containing metal fuel Alex/B, does not differ from HEM containing Alex. Increase the burning rate within the whole studied range of pressures does not exceed $10 \%\left(K_{3}\right)$. 


\section{Conclusions}

It was established experimentally that the efficiency of the effect of modified metal fuel on the burning rate HEM in subatmospheric pressure range increases with decreasing pressure.

Burning HEMs containing modified metal fuel is characterized by a decrease in the value of the exponent in the power-law burning rate in the considered range of subatmospheric pressures.

Replacement of aluminum by boron in a ratio of 2:1 leads to an increase in the burning rate HEMs containing metal fuel ASD-4/B) and practically does not affect the burning rate containing metal fuel Alex/B.

Funding was provided by Tomsk State University Competitiveness improvement Program (Project № 8.2.46.2015)

\section{References}

1. P. Pokhil, A. Belyaev, Y. Frolov, et al., Combustion of Powdery Metals in Active Media (Moscow, Nauka, 1972)

2. N. Bachmann, A. Belyaev, Combustion of Heterogeneous Condensed Systems (Moscow, Nauka, 1967)

3. G. Sakovich, V. Arkhipov, A. Vorozhtsov. Russian Nanotechnologies, 5, 89 (2010)

4. A. Gromov, E. Popenko, A. Korotkikh, et al., Physics and Chemistry of Combustion of the Metal Nanopowders in Nitrogen Gas Atmospheres (Tomsk, TSU Publishing House, 2007)

5. B. Trusov, Simulation of Chemical and Phase Equilibriums at High. Temperatures "Astra 4" (Moscow, 1991)

6. S. Sarner, Chemistry of Rocket Fuels (Moscow, Mir, 1968)

7. B. Zhukov, Energetic Condensed Systems. Brief Encyclopedic Dictionary (Moscow, Yanus-K, 2000)

8. V. Arkhipov, M. Gorbenko, T. Gorbenko, L. Savel'eva, Combustion, explosion end shock waves $\mathbf{4 5}$, 40 (2009) 